\title{
RESALE PRICE MAINTENANCE AND THE SERVICE ARGUMENT: EFFICIENCY EFFECTS
}

\author{
by \\ Norbert Schulz \\ Universität Würzburg
}

This version

05. Aug. 2005

\begin{abstract}
Proponents of RPM argue that RPM helps to sustain a high level of service at the point of sale and that such a high level is efficient. This paper provides a simple model which leads to the following conclusions: 1) RPM may increase or decrease the level of service. 2) Whether the service level is more efficient under RPM does not depend on the fact that service increases due to RPM. It may be lower under RPM and more efficient. 3) Whether the service level is more efficient depends on the characteristics of the heterogeneous consumers. A feature of the model which deviates from those found in the literature is the introduction of a class of consumers who do not search but decide on a purchase spontaneously.
\end{abstract}

Keywords: resale price maintenance, service, efficiency

JEL: L42, L13, K21

\section{Acknowledgment}

Helpful comments form seminar participants at the universities of Würzburg, Mannheim, and Darmstadt are greatfully acknowledged. 


\section{Resale Price Maintenance and the Service Argument: Efficiency Effects}

The issue of resale price maintenance (RPM) has a long history. In the English-speaking world one attributes its beginning to the pricing of Alfred Marshall's Principles of Economics (Breit (1991)). However, the evidence for RPM reaches back for a considerably longer time(Picot (1991)). But it is not merely a greeting from the distant past. Every once in while it becomes a hot topic. In March 2005 the Swiss Competition Commission (WeKo) prohibited a RPM arrangement of the Swiss book trade (WeKo (2005)). Germany had recently a debate on resale price maintenance in the book trade which led to the remarkable situation that resale price maintenance is mandatory by law in this sector (since 2002), while it is forbidden per se for all other sectors. These decisions are obviously in considerable conflict to each other.

Theoretically, this could reflect the ambivalent evaluation of RPM by the profession, where a positive attitude on the grounds of efficiency within a supply chain is counterbalanced by concerns about competition impeding effects. The efficiency defense for RPM is prominently connected to the service argument. Unconstrained price competition is said to lead to an inadequate supply of service. Hence, it does not come as a surprise that proponents of RPM in the Swiss and German book trade stressed this view. The free rider argument which posits that a customer may ask for product information (service) in one shop and than buy at a different shop which does not provide such information and can therefore offer the product at a cheaper price is one - albeit an extreme - variant of the efficiency argument. Indeed, in its extreme form this argument is not convincing in the book trade nor is it convincing in other sectors, where the price of a commodity is low relative to search costs. However, as Mathewson and Winter (1998) have stressed, the service argument is more general. Unconstrained price competition can erode the financial capability to provide high quality service. If service is valuable to consumers they might get hurt by abolishing RPM. Hence, there is scope for an efficiency rationale for RPM based on the service argument. Nevertheless it has long been acknowledged that RPM may induce such a high level of service that corresponding costs are not worth the potentially increased utility of consumers. We will return to this point in a moment.

For a considerable time the effects of RPM on impeded competition were connected to the fear that either producers or retailers could form a cartel more easily. As to the start of the German form of RPM in the book trade this 
has quite some evidence to its validity. Its beginnings are usually attributed to the fear of book sellers that mail order sellers may spoil their market. This would support the argument that retailers can form a cartel more easily, when RPM is available. This view is, however, dismissed by most commentators for the current situation in the book trade. But it is not claimed here that RPM does not have any relevance for cartel behavior. For a recent contribution on this issue see e.g. Rey and Vergé (2002). In the context of the present paper we will abstract from the consequences of RPM on cartelization and focus on the efficiency effects of the service argument in its pure form.

This question has been taken up in the literature before. Much of this literature has stressed a situation where firms use RPM to induce higher prices and service (e.g. Comanor (1985), Scherer and Ross (1990)). But it is known (e.g. R. Winter (1993)) that RPM may be used to increase or to decrease the level of point of sales service together with prices. Winter shows that price and service will increase due to RPM, if consumers are more sensitive to price competition than to service competition, but that price and service will decrease, if consumers are more sensitive to service competition than to price competition (this argument will be made more explicit in the main body of the paper). Winter's paper also provides a specific model of the demand side which supports the view that consumers are more sensitive to price competition - thus fuelling the predominant view that RPM increases prices and the level of service.

When the British RPM arrangement in the book trade (the net book agreement (NBA)) broke down around 1995, commentators reported that the prices for some books increased while prices decreased for other types of books (Monopolkommission (2000)). It is therefore one aim of the present paper to provide a simple parsimonious model of the demand side which allows for both consequences of RPM to occur.

This turns out to be desirable also from another perspective. The efficiency results in the present paper do not depend on whether RPM increases or decreases service and price. To the best of my knowledge this result cannot be found in the literature. Instead, whether RPM increases or decreases efficiency depends on the characteristics of two types of consumers which are modeled in the present paper.

Consumers of the first type choose the retail outlet which promises the best mix of service, price, and other characteristics of the outlet. These are modeled similarly to the demand side in Winter (1993). The second type consists of consumers who spontaneously decide to visit a store. They do not reason where to shop and do not compare retail outlets before a potential purchase. They just want to see whether there is something on offer which is worth its price. A considerable part of demand in many retail sectors is said to 
be due to this type of consumers. In the model of the present paper their presence is responsible for the fact that prices and service may decline due to RPM.

Some antitrust authorities like the Swiss competition commission (WeKo (2005)) argue that an increased demand due to higher service (induced by RPM) is a necessary condition for efficiency improvements due to RPM. In the model of the present model this condition is satisfied. But this property does not depend on demand-increasing service. RPM may increase demand also by decreasing price (and service) and this case can occur in our model. It is then argued, that in principle an efficiency evaluation has to weigh the change in consumer surplus against changes in profits. In principle this is true of course. But if the authority follows Comanor (1985) (as the WeKo decision does) an increase in demand which follows higher service due to RPM increases efficiency, if demand shifts up parallel due to increased service. The model of the present paper shows that is not necessarily the case. In fact the demand side of the present model has the property of parallel shifting demand, but efficiency may be higher under RPM or not. It very much depends on subtleties of the demand side and on the incentives of the manufacturer to counterbalance the desire of retailers to increase price. Hence, if Comanor is read as saying that a reasoned judgment on the efficiency effects of RPM is quite difficult in practice, the present paper strengthens this position. It is shown that efficiency can indeed rise or fall due to RPM despite the fact that the demand side has a simple linear structure.

The difference to the classic paper by Comanor is due to the fact that retailers have market power in the present paper and that the manufacturer uses non linear wholesale prices. This is in line with the contribution of Winter (1993). His paper makes no general claims with respect to welfare (with the exception of a numerical example, which point at a decrease of welfare due to RPM).

The remaining parts of the paper are organized as follows. Section 1 provides the model used in this paper together with some supporting arguments as to the modeling approach. Section 2 establishes the equilibrium result and section 3 establishes results on consumer surplus and welfare. Section 4 concludes and relates the result to different additional contributions in the literature.

\section{The model}

The general modeling approach follows closely that of R. Winter (1993). One monopolistic manufacturer produces goods which are sold by two sellers to 
the consumers. This fits the situation in the book trade quite well. The product is a book title and its copyright belongs to exactly one publisher. The retail sector of this trade is not particularly concentrated but some (local) market power is certainly relevant. Modeling competition as a duopoly without much bargaining power vis à vis the manufacturer seems therefore adequate. From this it should be clear that interbrand competition is not modeled. We add some remarks on this obvious omission in section 3 .

According to many observers goods like books or textiles are often bought by incidence. A consumer strolling through a city may suddenly decide to visit a store and to find out what is on offer, although he had no intent to do so, when he decided to go downtown. Customers of this type typically do not actively search. Once a store is entered he only decides whether or not a good that he finds promising is worth its price. But he will not visit another store in order to search for a better price (in a world without RPM). If all consumers were of this type there would be no essential role for competition among retailers but for showy appearances in order to attract the consumers attention. A bookstore could more or less act like a local monopolist. In the framework of our model this would have the consequence that non linear prices and RPM are perfect substitutes for the manufacturer. This will become clear in a moment.

Certainly, not all consumers are of this type. Some decide to go downtown in order to buy e.g. a specific book or a book of a certain type ( a novel or a textbook). These consumers will also decide ex ante where to buy. They may prefer one store to another because it is closer in distance or because it exhibits a nicer atmosphere. But they may also decide on the grounds of information about price and service quality at that store.

Our model allows for both types of consumers. This deviates from the demand model in R. Winter (1993) which only captures the second type of consumers. We follow Winter to a large extent in modeling this type of consumers which we call choosey consumers. But we simplify his model by assuming that these consumers will buy one unit of the good in any case which seems adequate in this context. Stores are modeled as being located at the end points of a Hotelling line of length 1. There is a continuum of consumers each characterized by its location on the line. As usual the location can be interpreted geographically or in terms of product differentiation (atmosphere, appearance, internet shop versus mortar and brick store). The distribution of consumers with respect to their location is assumed to be uniform (another simplification compared with Winter). The mass of these consumers is denoted by $\beta$.

The service level and the price of store $i$ is denoted by $s_{i}$ and $p_{i}$ resp. The service should be interpreted as dedicated to a specific good like a book title. 
It may include personnel being well acquainted with the good and thus being able to advise customers properly or it may include presenting the good at a prominent place or providing reports by critics on its content and quality in the case of a book.

The utility of a consumer located at $\alpha$ when patronizing store 1 (which is located at 0 ) is assumed to be

$$
B-e s_{1}-p_{1}-b \alpha
$$

An analogous expression denotes the utility of this consumer when he purchases the good at store 2 (which is located at 1 and therefore $\alpha$ has to be replaced by $1-\alpha$ ). Demand for store 1 stemming from this type of consumers is

$$
\frac{\beta}{2}+\frac{e \beta}{2 b}\left(s_{1}-s_{2}\right)+\frac{\beta}{2 b}\left(p_{2}-p_{1}\right)
$$

with an analogous expression for the demand facing store 2. This presupposes that $B$ is large enough such that all consumers of this type buy one unit of the good.

The class of spontaneous consumers is characterized by the utility

$$
A+l s_{i}-p_{i}
$$

when a consumer visits store $i$. These customers differ in their reservation utility $A_{0}$ which is distributed uniformly in $\left[0, A^{*}\right]$, where $A^{*}$ is large enough, such that the demand at store $i$ from spontaneous customers is equal to the expression denoting the utility of a customer. Hence demand from both types of consumers patronizing store $i$ is:

$$
D_{i}\left(p_{i}, p_{j}, s_{i}, s_{j}\right)=A+l s_{i}-p_{i}+\frac{\beta}{2}+\frac{e \beta}{2 b}\left(s_{i}-s_{j}\right)+\frac{\beta}{2 b}\left(p_{j}-p_{i}\right)
$$

As for the cost structure of the firms we assume that the manufacturer has constant marginal cost which we normalize to 0 and some fixed cost which are sufficiently small to not influence the decision variables of the publisher. Therefore the fixed cost will be neglected in the following. The provision of service is costly to the stores. Providing the level of $s_{i} \operatorname{costs} c s_{i}^{2} / 2$.

The pricing behavior of the manufacturer vis à vis the sellers follows again Winter (1993). The manufacturer charges store $i$ a price $q_{i}$ per unit of the good and a fee $F_{i}$ independently of the volume of sales. This captures among other things the use of rebates which are quite common in the relationship between 
manufacturers and retailers. It also provides the manufacturer with an instrument to work against the problem of double marginalization.

The profit of store $i$ is therefore:

$$
\pi_{i}\left(p_{i}, p_{j}, s_{i}, s_{j}\right)=\left(p_{i}-q_{i}\right) D_{i}\left(p_{i}, p_{j}, s_{i}, s_{j}\right)-c s_{i}^{2} / 2-F_{i}
$$

Without RPM stores choose their level of price and service given $q_{i}$ and $F_{i}$. With RPM the price is fixed by the manufacturer and the stores can only choose their level of service. In slight misuse of notation we denote the equilibrium choices as $p_{i}(\cdot)$ and $s_{i}(\cdot)$ in both cases.

The manufacturers profit is

$$
\Pi=\sum_{i=1}^{2}\left(q_{i} D_{i}\left(p_{i}(\cdot), p_{j}(\cdot), s_{i}(\cdot), s_{j}(\cdot)\right)+F_{i}\right)
$$

where under RPM $p_{i}(\cdot)$ equals the price which the manufacturer chooses.

As the manufacturer has the possibility of charging non linear prices to retailers, it should be clear that he cannot gain anything if only spontaneous consumers exit $(\beta=0)$. Both retailers are just (local) monopolists in this case and RPM and nonlinear prices are perfect substitutes to the manufacturer.

\section{The consequences of RPM for prices and service}

Given the complete symmetry of the stores we will concentrate on symmetric equilibrium configurations. Hence prices and service levels are equal for both stores. Under RPM prices are of course equal by definition of RPM.

At some stages it will be convenient to ease notation by denoting $A+\beta / 2$ as $a, e \beta / 2 b$ as $w$ and $\beta / 2 b$ as $d$. Thus store $i$ now faces demand

$$
D_{i}\left(p_{i}, p_{j}, s_{i}, s_{j}\right)=a+l s_{i}-p_{i}+w\left(s_{i}-s_{j}\right)+d\left(p_{j}-p_{i}\right)
$$

The demand system as modeled by Winter (1993) yields a clear answer with respect to the consequences of RPM for prices and service: It increases both prices and service. This is not the case in our model: With RPM the price and the service level turns out to be

$$
p_{R P M}=\frac{a c}{2 c-l^{2}} \quad S_{R P M}=\frac{a l}{2 c-l^{2}} .
$$

The appendix provides a proof of this result as well as proofs for all other assertions in this and the following section. At this point it should be noted 
that we impose some parameter restrictions which guarantee concavity of the relevant profit functions. They also imply that all prices are positive.

With RPM the parameters reflecting some competition among the stores, $w$ and $d$, play no role. This is to be expected. RPM eliminates any role for price competition. Equal prices imply that the manufacturer is exclusively interested in aggregate demand which does not depend on $w$.

If RPM is not an option for the manufacturer, prices and service turn out to be

$$
\begin{aligned}
& p_{c}=\frac{a\left(c(1+d)^{2}-d l(l+w)+w(l+w)\right)}{2 c(1+d)^{2}-(1+2 d) l(l+w)+w(l+w)} \\
& s_{c}=\frac{a(1+d)(l+w)}{2 c(1+d)^{2}-(1+2 d) l(l+w)+w(l+w)}
\end{aligned}
$$

As is evident from these expression, $p_{R P M}$ and $p_{c}$ do not coincide in general and the same is true for $s_{R P M}$ and $s_{c}$. It is also clear that the publisher's profit will be less in general, if RPM is not available. With RPM he could otherwise choose $p_{c}$ as retail price and ask a price $q_{i}$ such that stores would choose $s_{c}$. As the optimal decision under RPM differs from these levels it must be true that the profit of the manufacturer is smaller without RPM.

In terms of comparison we can state the following proposition, which turns out to be more transparent, if we return to the notation at the beginning of this section:

Proposition 1: (a) If $e<l$ then $p_{R P M}>p_{c}$ and $s_{R P M}>s_{c}$.

(b) If $e>l$ then $p_{R P M}<p_{c}$ and $s_{R P M}<s_{c}$.

Hence depending on the parameter values prices and service may move in different directions if RPM is enabled. Only if $e=l$ nothing changes. Note that $e>l$ means that an increase in service increases the utility of choosey consumers by more than the utility of spontaneous consumers. An increase in service attracts more choosey consumers than spontaneous consumers. Without RPM this is more attractive, as stores can set higher prices to cover the increased cost of service.

This result may help to explain why prices of different types of books developed in different directions when the NBA broke down. The demand for scientific literature could be argued to be quite insensitive to service for those customers who visit a book store based on an conscious ex ante decision to buy a specific title. Well trained personnel in the content or presentation should play a very minor role for those customers. For spontaneous customers 
a prominent presentation may be a welcome reminder that they always wanted to buy this book. Hence $e<l$ captures this situation and in line with our result the prices of scientific books are reported to have declined after the NBA breakdown. The price of pocket books on the other hand increased. At least for novels this is also consistent with our theoretical result. Think of the situation that you only know that you want to buy a novel of a specific genre. Then well trained personnel becomes important as well as the presentation in the store which speaks for a high $e$. For spontaneous customers the advice of trained personnel is not that important, as they just browse around. This speaks for a relatively small $l$. It is not claimed here that these arguments explain the movement of prices in Great Britain fully. There are many more influences than we capture in this simple model. But the facts seem quite consistent with the result.

Winter (1993) points out that RPM will increase prices if and only if

$$
\frac{\varepsilon_{p}^{r}}{\varepsilon_{p}^{M}}>\frac{\varepsilon_{s}^{r}}{\varepsilon_{s}^{M}}
$$

where $\varepsilon_{p}$ denotes the price elasticity and $\varepsilon_{s}$ denotes the service elasticity of demand. The index $M$ relates to the elasticities at the market level while the index $r$ relates to the elasticities at the level of one retailer. One way of interpreting this equality is thus: If at the level of one retailer consumers are easier attracted by a decrease in price than by an increase in service, than competition among stores will drive down prices. As service is worth less it will also decrease. RPM can than be used to stabilize a higher level of service. In Winter's model the demand system satisfies this inequality.

Given that this characterization for a price increasing effect of RPM is quite general (at least locally) it is not surprising that Proposition 1 is fully consistent with this inequality. The condition in part (a) can easily be checked to be a special case of the above inequality. But - deviating from Winter - our demand system is flexible enough to allow for the reversed inequality to hold, which is the case in part (b). As we have seen, casual empirical evidence supports the view that both directions of prices can be observed after RPM is no longer practiced.

As the level of demand plays an important role in some arguments on the efficiency of the service level due to RPM it seems adequate to note the following corollary:

Corollary : Market demand increases due to RPM if and only if $e \neq l$. 
Moreover market demand has the form $2(a+l s-p)$. Hence it has the parallel shifting property mentioned in Comanor (1985).

\section{The consequences of RPM on consumer surplus and welfare}

If we want to compare welfare under RPM with welfare without RPM, this is extremely easy for $e=l$. In this case the same prices and service levels obtain whether RPM is an option of the manufacturer or not. Hence, profits, consumer surplus of both types of customers, and (therefore) welfare are not affected by RPM. For all other parameter constellations a direct comparison turns out to be very messy. However, consumer surplus and welfare can be taken as functions of the taste parameter $e$. Using the mathematical properties of these functions provides some clear characterizations.

It is convenient to analyze the surplus of both types of customers first. For the type of spontaneous consumers we find that they are always better off under RPM, as long as $e \neq l$ :

Proposition 2: For $e \neq l$ consumer surplus of spontaneous consumers, $C S^{s p}$, is always larger with RPM than without RPM.

Intuitively, this is due to the fact that without RPM retailers have more freedom to adapt the service levels to the wishes of the choosey consumers. If these consumers derive a higher utility from service $(e>l)$, it is possible to pass the increased costs by higher prices (as we have seen in the last section). The same holds true if choosey consumers derive less utility. Then prices will decrease. Hence, without RPM service and price will be more aligned with the wishes of the choosey customers and less so with the wishes of the spontaneous customers (relative to the RPM choices). Therefore spontaneous customers suffer from the prohibition of RPM. This same intuition helps also explain why choosey consumers suffer from RPM:

Proposition 3: For $e \neq l$ consumer surplus of choosey consumers, $C S^{c h}$, is always smaller with RPM than without RPM.

While profits are always higher under RPM (for $e \neq l$ ), consumer surplus of both types of consumers are inversely affected by RPM. From what we developed so far, we cannot say whether the loss of consumer surplus of one type is dominated by gains of the other type of consumers and firms. Intuitively one might think that RPM is welfare reducing if the group of choosey consumers is large enough $(\beta)$. But this turns out not to be true. The 
number of choosey consumers has an impact on prices and service which is to the detriment of the other groups if RPM is not allowed. Hence RPM may profit these groups too much to render welfare smaller under RPM.

Fortunately, it possible to derive a local result at $e=l$ :

Proposition 4: In a neighborhood of $e=l$ welfare is

(a) higher under RPM (for $e \neq l$ ), if $A$ is large enough and

(b) lower under RPM (for $e \neq l$ ), if $b$ is large enough.

Part (a) of proposition 4 is intuitive given the results obtained so far. $A$ is the basic utility of spontaneous consumers. If $A$ increases, more spontaneous consumers will purchase a unit of the good. Hence, the utility of this group will increase if $A$ does. As this group becomes more important and as it profits from RPM, part (a) does not come as surprise.

Part (b) is bit more subtle. Suppose we are in situation without RPM. Let us start with the reaction of price and service to an increase of $e$, starting from $e=l$. As is clear from proposition 1 price and service will both increase. Now $b$ decreases the service and the price elasticity of demand. Hence cet. par. retailers have an incentive to charge higher prices and offer lower service, if $b$ is increased. As in the double marginalization problem this is not in the interest of the manufacturer. Hence he will decrease his wholesale price to counteract this effect. In the present model the combined effect is that prices and service will increase more due to an increase in $e$, if $b$ is larger. Furthermore price and service changes are such that the utility of spontaneous consumers is not affected locally. But the choosey customers gain for $e>l$, as they value the increased service higher. As due to an increased $b$ this increase in service is higher, choosey costumers gain more. If this gain is sufficiently large, welfare increases if RPM is not allowed or phrased otherwise, welfare decreases under RPM.

Note that the result does not depend on whether RPM induces higher or lower levels of service. Rather it depends on which group of consumers is more affected by RPM.

It should also be noted that we have abstained from modeling interbrand competition in any way. This is a serious omission of course. While it is true in the book trade that a publisher usually holds an exclusive copyright on a book title, books of similar types are substitutable to a certain extent. It is a frequent result in the study of vertical restraints that negative efficiency effects are weakened by interbrand competition (cp. Motta (2004)). But usually these negative effects remain in existence whenever competition is not very intense. And thus the warning included in proposition 4 that RPM may have negative consequences in terms of efficiency seems justified. 


\section{Concluding remarks}

The paper introduces a specification of the demand side which allows RPM to have different effects on prices and on service, which may increase or decrease due to RPM.

A feature of the model which deviates from those found in the literature is due to the introduction of a class of customers who do not search but decide on a purchase spontaneously. This is certainly an adequate modeling strategy with respect to the book trade. But it is also adequate for other product markets, especially those where the price of the commodity represents a relatively small fraction of the consumer's budget.

While the prices and the service level are influenced by the relative importance of those consumers who do search, the qualitative effect of RPM on prices and service are not affected, as can be easily checked.

The findings of the paper support the view that RPM may have an efficiency enhancing potential which always sheds doubt on a per se prohibition of RPM - especially when other forms of vertical restraints are not prohibited per se. But the opposite effect may also arise. RPM may be efficiency reducing. Moreover, even in the restricted environment of the model, the judgment of whether RPM is detrimental to efficiency or not depends on much more delicate tradeoffs as found in the literature. Simple indications such as an increased demand due to higher service are found to provide neither a necessary nor a sufficient condition for RPM to enhance efficiency.

The most serious omissions of the model concern the absence of competition among manufacturers and the absence of uncertainty which certainly is of considerable importance e.g. for the production of a specific book. Competition is only very loosely incorporated in the model as the cost of service can be interpreted as the opportunity cost of not providing prominent shelf space or informational service for other goods (of a rival manufacturer). Given the vast number of retail items available shelf space is certainly scarce and it also impossible for the personnel to be properly informed about all items of certain genre.

There are some contributions to the literature dealing with the scarcity of shelf space in the retail sector, most prominently by Shaffer (1991a, 1991b). However, both papers give a minor role to retail competition. In Shaffer (1991b) a multi-product monopolist tries to convince retailers (which all enjoy a local monopoly) to stock their full line of products. It is shown that one possibility of reaching the full integration result consists in imposing RPM and paying a flat fee for shelf space. Competition is only present, as retailers have the option to use their shelf space for presentation of 
commodities of another competitive industry which is not specified more precisely. Aside from the fact that competition is not modeled in detail, the desire to be present on the shelves of a book store seems to be of less importance in the book trade contrary to the situation in other industries. At least in Germany, publishers are not known to buy prominent shelf space as is the case in other sectors. This is probably at least partly due to the fact that a well organized whole-sale market exists In Shaffer (1991a) manufacturers are perfectly competitive and sell to retailers with considerable market power. This scenario seems not well suited for the book trade in Germany. Contributions which address the service argument for RPM in a context of interbrand as well as intrabrand competition are not known to the best of my knowledge.

The success of new goods, such as books, is usually very uncertain at the time of production. The management of the corresponding risk is therefore an important part of the strategy of manufacturers and retailers alike. Deneckere et al. $(1996,1997)$ have taken up demand uncertainty and its relationship to RPM in two remarkable papers. They show that a monopolistic manufacturer has an incentive to impose RPM on its sales to perfectly competitive retailers and that this imposition may (but need not) improve welfare and even expected consumer surplus. One driving force of the result is that retailers have to order inventories before uncertainty unveils and that the costs of these inventories are completely sunk. Again while a very interesting result by itself it fits the book trade less well. The uncertainty in those papers deals with the demand of one specific homogenous commodity. If a manufacturer produces essentially one product this is a suitable modeling strategy. A publisher, however, produces a whole line of new books each year. Possibilities to form a less risky portfolio of titles are open to a publisher. In addition, it is quite common that publishers take back unsold inventories. Hence costs related to inventories are not completely sunk. But this drives the results of those papers. Hence, it is not clear how the results would change if both aspects of the book trade would be incorporated, let alone the main issue of the present paper: the service argument.

\section{References}

Breit, W. (1991): Resale Price Maintenance: What do Economists Know and When did They Know, Journal of Institutional an Theoretical Economics, vol. 147, pp. 72-90

Comanor, W. (1985): Vertical Price-Fixing, Vertical Market Restrictions, and the New Antitrust Policy, Harvard Law Review, vol. 98, pp. 983-1002 
Deneckere, R., Marvel, H., and J. Peck (1996): Demand Uncertainty, Inventories, and Resale Price Maintenance, Quarterly Journal of Economics, vol. 111, pp. 885-914

Deneckere, R., Marvel, H., and J. Peck (1997): Demand Uncertainty and Price Maintenance: Markdowns as Destructive Competition, American Economic Review, vol. 87, pp. 619-641

Mathewson, F. and R. Winter (1998): The Law and Economics of Resale Price Maintenance, Review of Industrial Organization, vol. 13, pp. 5784

Monopolkommission (2000): Wettbewerbspolitk in Netzstrukturen, Hauptgutachten 1998/1999, Bonn

Motta, M. (2004): Competition Policy, Oxford University Press

Picot, A. (1991): Resale Price Maintenance: What do Economists Know and When did They Know, Comment, Journal of Institutional an Theoretical Economics, vol. 147, pp. 94-98

Rey, P. and T Vergé (2002): Resale Price Maintenance and Horizontal Cartel, CPMO Working Paper, No. 02/47

Scherer, F. M. and D. Ross (1990): Industrial Market Structure and Economic Performance, Houghton Mifflin Company

Shaffer, G. (1991a): Slotting Allowances and Resale Price Maintenance: A Comparison of Facilitating Practices, Rand Journal of Economics, Vol. 22, pp. $120-135$

Shaffer, G. (1991b): Capturing Strategic Rent: Full-Line Forcing, Brand Discounts, Aggregate Rebates, and Maximum Resale Price Maintenance, Journal of Industrial Economics, vol. 34, pp. 557-575

WeKo (2005): Verfügung der Wettbewerbskommission vom 21.März 2005, http://www.weko.admin.ch/news/00008/Buchpreisbindung.pdf

Winter, R. (1993): Vertical Control, and Price Versus Nonprice Competition, The Quarterly Journal of Economics, February, pp. 61-76 


\section{Appendix A1: Prices and Service with RPM}

Recall that demand can be written as

$$
D_{i}\left(p_{i}, p_{j}, s_{i}, s_{j}\right)=a+l s_{i}-p_{i}+w\left(s_{i}-s_{j}\right)+d\left(p_{j}-p_{i}\right)
$$

and that the aim of the manufacturer is to maximize

$$
\Pi=\sum_{i=1}^{2}\left(q_{i} D_{i}\left(p_{i}(\cdot), p_{j}(\cdot), s_{i}(\cdot), s_{j}(\cdot)\right)+F_{i}\right) .
$$

The usual argument applies to show that $F_{i}$ will be set such that retailers obtain a reservation profit of 0 . This implies

$$
F_{i}=\left(p_{i}-q_{i}\right) D_{i}\left(p_{i}, p_{j}, s_{i}, s_{j}\right)-c s_{i}^{2} / 2
$$

and the profit of the manufacturer becomes:

$$
\Pi=\sum_{i=1}^{2}\left(p_{i} D_{i}\left(p_{i}(\cdot), p_{j}(\cdot), s_{i}(\cdot), s_{j}(\cdot)\right)-c s_{i}^{2} / 2\right)
$$

As prices are equal for both retailers with RPM, this reads in more specific terms:

$$
\Pi=p\left(2 a+l\left(s_{1}+s_{2}\right)-2 p\right)-c\left(s_{1}^{2}+s_{2}^{2}\right) / 2
$$

Suppose the manufacturer could directly set $p$ and both $s_{i}$. Then maximizing the profit would yield the first order conditions:

$$
\begin{gathered}
2 a+l\left(s_{1}+s_{2}\right)-4 p=0 \\
p l-c s_{i}=0
\end{gathered}
$$

Solving this system gives the expressions for $p_{R P M}$ and $s_{R P M}$.

For these expressions to make sense, $c$ has to be large enough which is assumed in the following (cp. assumption A1 in appendix A2).

In our setup the manufacturer cannot directly set $s_{R P M}$. It remains to be shown that he can implement this level of service by charging a suitable price $q_{i}$ to the retailers. In the RPM context the profit of retailer $i$ is:

$$
\pi_{i}=\left(p-q_{i}\right)\left(a+l s_{i}-p+w\left(s_{i}-s_{j}\right)\right)-c s_{i}^{2} / 2-F_{i}
$$

Maximizing with respect to $s_{i}$ gives the first order condition: 


$$
\left(p-q_{i}\right)(l+w)=c s_{i}
$$

In order to obtain the service level $s_{R P M}$, the manufacturer should therefore set $q_{i}$ according to

$$
q_{i}=p_{R P M}-\frac{c s_{R P M}}{l+w}=\frac{a c}{2 c-l^{2}}-\frac{a c l}{\left(2 c-l^{2}\right)(l+w)}=\frac{a c w}{\left(2 c-l^{2}\right)(l+w)}
$$

which establishes the result.

\section{Appendix A.2 Prices and service without RPM}

If retailers choose their price as well as the service level the profit takes the form

$$
\pi_{i}=\left(p_{i}-q_{i}\right)\left(a+l s_{i}-p_{i}+w\left(s_{i}-s_{j}\right)+d\left(p_{j}-p_{i}\right)\right)-c s_{i}^{2} / 2-F_{i}
$$

which is concave in the retailers own price and service level, if $c$ is large enough. More specifically we will assume:

$$
\text { (A1) } \quad c(1+d)>\max (l, w)(l+w)
$$

The first order conditions can be written as:

$$
\text { (1) } \quad a+q_{i}(1+d)+(l+w) s_{i}-w s_{j}-2(1+d) p_{i}+d p_{j}=0
$$

$$
\text { (2) } \quad\left(p_{i}-q_{i}\right)(l+w)-c s_{i}=0
$$

Solving (2) for $s_{i}$ and inserting the result in (1) gives:

$$
\text { (3) } \begin{aligned}
a+q_{i}(1+d)-q_{i} \frac{(l+w)^{2}}{c}+ & q_{j} \frac{w(l+w)}{c} \\
& -\left(2(1+d)-\frac{(l+w)^{2}}{c}\right) p_{i}+\left(d-\frac{w(l+w}{c}\right) p_{j}=0
\end{aligned}
$$

As announced in the main body of the paper we will concentrate on the symmetric solutions. Hence we posit $q_{1}=q_{2}=q$ and this implies $p_{1}=p_{2}=p$. Then (3) becomes:

$$
a c+q((1+d) c-l(l+w))=((2+d) c-l(l+w)) p
$$

which gives 


$$
\text { (4) } p(q)=\frac{a c+q((1+d) c-l(l+w))}{(2+d) c-l(l+w)}
$$

Inserting this back into the solution of (2) gives

$$
\text { (5) } s(q)=\frac{(a-q)(l+w)}{(2+d) c-l(l+w)}
$$

For the same reasons as in appendix A.1 the profit of the manufacturer can now be written as

$$
\Pi=p(q)\left(D_{1}(p(q), s(q))+D_{2}(p(q), s(q))\right)-c s^{2}(q)
$$

Note that the first order conditions for the retailers' equilibrium have the form:

$$
\begin{aligned}
& \text { (1a) }\left(p_{i}-q\right) \frac{\partial D_{i}}{\partial p_{i}}+D_{i}=0 \\
& \text { (2a) } \quad\left(p_{i}-q\right) \frac{\partial D_{i}}{\partial s_{i}}-c s_{i}=0
\end{aligned}
$$

This form will be used in a moment. Consider now the first order condition for maximizing the manufacturer's profit with respect to $q$ :

$$
\begin{aligned}
& \frac{\partial p}{\partial q}\left(\left[D_{1}+p \frac{\partial D_{1}}{\partial p_{1}}+p \frac{\partial D_{2}}{\partial p_{1}}\right]+\left[D_{2}+p \frac{\partial D_{2}}{\partial p_{2}}+p \frac{\partial D_{1}}{\partial p_{2}}\right]\right)+ \\
& \frac{\partial s}{\partial q}\left(\left[p \frac{\partial D_{1}}{\partial s_{1}}+p \frac{\partial D_{2}}{\partial s_{1}}-c s\right]+\left[p \frac{\partial D_{2}}{\partial s_{2}}+p \frac{\partial D_{1}}{\partial s_{2}}-c s\right]\right)=0
\end{aligned}
$$

Using $(1 a)$ and $(2 a)$ this yields:

$$
\begin{aligned}
& \frac{\partial p}{\partial q}\left(\left[q \frac{\partial D_{1}}{\partial p_{1}}+p \frac{\partial D_{2}}{\partial p_{1}}\right]+\left[q \frac{\partial D_{2}}{\partial p_{2}}+p \frac{\partial D_{1}}{\partial p_{2}}\right]\right)+ \\
& \frac{\partial s}{\partial q}\left(\left[q \frac{\partial D_{1}}{\partial s_{1}}+p \frac{\partial D_{2}}{\partial s_{1}}\right]+\left[q \frac{\partial D_{2}}{\partial s_{2}}+p \frac{\partial D_{1}}{\partial s_{2}}\right]\right)=0
\end{aligned}
$$

and using the specific expressions for the demand system gives:

$$
2\left(\frac{\partial p}{\partial q}[-q(1+d)+d p]+\frac{\partial s}{\partial q}[q(l+w)-p w]\right)=0
$$


Inserting the derivatives of (4) and (5) this condition now reads:

$$
((1+d) c-l(l+w))(-q(1+d)+d p)-(l+w)(q(l+w)-p w)=0
$$

Next insert $p$ according to (4). After a series of rearrangements this can be rewritten as.

$$
a[(1+d) c d-l(l+w) d+w(l+w)]-\left[2(1+d)^{2} c-(1+2 d) l(l+w)+w(l+w)\right] q=0
$$

Note that under assumption (A1) the second expression in brackets is positive. It follows that the profit function of the publisher is concave in $q$.

Hence, the manufacturer will charge each seller a price of

$$
\text { (6) } q=\frac{a[(1+d) c d-l(l+w) d+w(l+w)]}{2(1+d)^{2} c-(1+2 d) l(l+w)+w(l+w)}
$$

The remaining steps are conceptually simple: just insert (6) into (4) and (5). As doing these steps and getting the result in the main part of the paper is not that straightforward we offer some details here. Let us start with the price. Inserting (6) into (4) gives

$$
\begin{aligned}
& ((2+d) c-l(l+w)) p / a= \\
& \quad c+((1+d) c-l(l+w)) \frac{(1+d) c d-l(l+w) d+w(l+w)}{2(1+d)^{2} c-(1+2 d) l(l+w)+w(l+w)}
\end{aligned}
$$

The right hand side of the equation above can therefore be written as:

$$
\begin{aligned}
& \frac{c\left(2 c(1+d)^{2}-(1+2 d) l(l+w)+w(l+w)\right)}{2(1+d)^{2}-(1+2 d) l(l+w)+w(l+w)} \\
& +\frac{((1+d) c-l(l+w))((1+d) c d-l(l+w) d+w(l+w)}{2(1+d)^{2}-(1+2 d) l(l+w)+w(l+w)}
\end{aligned}
$$

Next we focus on the numerator of this expression. Note that

$$
2 c(1+d)^{2}=(1+d)(2+d) c+(1+d) c d
$$

Therefore we can write the numerator as follows:

$$
\begin{gathered}
c(1+d)((2+d) c-l(l+w))+c d((1+d) c-l(l+w))+c w(l+w)+c^{2} d(1+d)^{2}- \\
2 c d l(l+w)-2 c d^{2} l(l+w)+d l^{2}(l+w)^{2}+c\left(1+d 9 w(l+w)-l w(l+w)^{2}\right. \\
=c(1+d)[(2+d) c-l(l+w)]+w(l+w)[(2+d) c-l(l+w)]+
\end{gathered}
$$




$$
\begin{gathered}
c^{2} d(1+d)(2+d)-3 c d l(l+w)-2 c d^{2}(l+w)+d l^{2}(l+w)^{2} \\
=c(1+d)[(2+d) c-l(l+w)]+w(l+w)[(2+d) c-l(l+w)]+ \\
c^{2} d(1+d)(2+d)+d l(l+w)[l(l+w)-(2+d) c]-(1+d) c d l(l+w) \\
=[(2+d) c-l(l+w)]((1+d) c+w(l+w)-d l(l+w)+(1+d) c d)
\end{gathered}
$$

From this expression the result for the price in the main body of the paper follows immediately. Deriving the result for $s$ poses no problems.

\section{Appendix A3 Comparison of prices and service levels}

Let us start with a comparison of the service levels:

$$
\begin{gathered}
s_{c}=\frac{a(1+d)(l+w)}{2 c(1+d)^{2}-(1+2 d) l(l+w)+w(l+w)}<s_{R P M}=\frac{a l}{2 c-l^{2}} \\
\left.\Leftrightarrow(1+d)(l+w)\left(2 c-l^{2}\right)<l \mid 2 c(1+d)^{2}-(1+2 d) l(l+w)+w(l+w)\right] \\
\Leftrightarrow 2 c(1+d)(w-d l)<l(l+w)(w-d l)
\end{gathered}
$$

Because of assumption A1 this is equivalent to $w<d l$.

The price with RPM is higher than the price without RPM iff

$$
\begin{gathered}
p_{R P M}=\frac{a c}{2 c-l^{2}}>p_{c}=\frac{a\left[c(1+d)^{2}-d l(l+w)+w(l+w)\right]}{2 c(1+d)^{2}-(1+2 d) l(l+w)+w(l+w)} \\
\Leftrightarrow c\left[l^{2}(1+d)^{2}-(l+w)^{2}\right]>l^{2}(l+w)(d l-w) \\
\Leftrightarrow(d l-w)[l((2+d) c-l(l+w))+c w]>0
\end{gathered}
$$

Again given assumption A1 this is equivalent to $w<d l$. Using the definition $w$ and $d$, this establishes proposition 1 .

Market demand equals in the absence of RPM $2\left(a+l s_{c}-p_{c}\right)$. Inserting the expressions for $s_{c}$ and $p_{c}$ gives: 


$$
a c \frac{2(1+d)^{2}}{2 c(1+d)^{2}-(1+d) l(l+w)+(w-d l)(l+w)}
$$

Note that $s_{c}=s_{R P M}$ and $p_{c}=p_{R P M}$ for $e=l$. e enters the demand only via $w$. As $s_{R P M}$ and $p_{R P M}$ do not depend on $w$ market demand under RPM is constant in $e$. Consider now market demand without RPM as given above. Market demand depends on $w$ and thus on $e$. The monotonicity properties of market demand with respect to $e$ are the same as with respect to $w$. Therefore we will look at the derivative market demand with respect to $w$ :

$$
\frac{2 a c(1+d)^{2} 2(d l-w)}{\left[2 c(1+d)^{2}-(1+d) l(l+w)+(w-d l)(l+w)\right]^{2}}
$$

Hence market demand increases iff $d l>w$ or equivalently $l>e$. This implies that market demand as function of $e$ increases up to $l$ and decreases from this value onwards. Its maximum is attained at $e=l$ where it reaches its RPM level. This proves the Corollary.

\section{Appendix A4 Consumer and Social surplus effects}

The aggregate gross utility of spontaneous customers patronizing bookstore $i$ is

$$
\int_{0}^{A+l s_{i}-p_{i}}\left(A+l s_{i}-A_{0}\right) d A_{0}=\frac{1}{2}\left(A+l s_{i}-p_{i}\right)\left(A+l s_{i}+p_{i}\right)
$$

Consumer surplus of these consumers is

$$
\frac{1}{2}\left(A+l s_{i}-p_{i}\right)^{2}
$$

Hence, given the symmetry of the model total consumer surplus is

$$
C S_{c}^{s p}(e)=\left(A+l s_{c}-p_{c}\right)^{2}
$$

without RPM and

$$
C S_{R P M}^{s p}(e)=\left(A+l s_{R P M}-p_{R P M}\right)^{2}
$$


with RPM. Again $C S_{R P M}^{s p}$ does not depend on $e . C S_{c}^{s p}$ depends on $e$ via prices and service levels and attains the same value as $C S_{R P M}^{s p}$ at $e=l$. This function will rise and fall iff the expression in parantheses rise and fall. In turn this expression rises and falls under the same conditions as market demand does. From this it follows that is $C S_{c}^{s p}$ quasi-concave attaining its maximum at $e=$ l. This proves proposition 2 .

Given the symmetric configurations the aggregate gross utility of the choosey type of customers patronizing bookstore $i$ is

$$
\beta \int_{0}^{0,5}\left(B+e s_{i}-b \alpha\right) d \alpha=\frac{\beta B}{2}+\frac{\beta e s_{i}}{2}-\frac{\beta b}{8}
$$

This implies that total consumer surplus is

$$
\beta B-\beta b / 4+\beta(e s-p)
$$

$C S_{c}^{c h}$ denotes consumer surplus of choosey consumers, if RPM does not prevail and $C S_{R P M}^{c h}$ if it does. We will look at the properties of $C S_{c}^{c h}-C S_{R P M}^{c h}$ :

$$
C S_{c}^{c h}(e)-C S_{R P M}^{c h}(e)=\beta e\left(s_{c}-s_{R P M}\right)-\beta p_{c}+\beta p_{R P M}
$$

We will check the monotonicity properties of this function. Therefore we differentiate this function with respect to $e$ :

$$
\text { (7) } \beta\left(s_{c}-s_{R P M}\right)+\beta\left(e \frac{\partial s_{c}}{\partial w}-\frac{\partial p_{c}}{\partial w}\right) \frac{\beta}{2 b}
$$

Note that the first term is positive iff $e>l$. Differentiating $s_{c}$ with respect to $w$ gives:

$$
\frac{\partial s_{c}}{\partial w}=\frac{a(1+d)\left(2 c(1+d)^{2}-(l+w)^{2}\right)}{\left[2 c(1+d)^{2}-(1+d) l(l+w)+(w-d l)(l+w)\right]^{2}}
$$

Differentiating $p_{c}$ with respect to $w$ gives :

$$
\frac{\partial p_{c}}{\partial w}=\frac{a(l+w)\left(2 c(1+d)^{2}-(1+d) l(l+w)\right)}{\left[2 c(1+d)^{2}-(1+d) l(l+w)+(w-d l)(l+w)\right]^{2}}
$$

Inserting these expression into the bracket in the second expression in (7) gives: 


$$
\frac{a(1+d)(e-l)\left(2 c(1+d)-(l+w)^{2}\right)}{\left[2 c(1+d)^{2}-(1+d) l(l+w)+(w-d l)(l+w)\right]^{2}}
$$

Given assumption $\mathrm{A} 1$ this expression is positive iff $e>l$. Hence, $C S_{c}^{c h}-$ $C S_{R P M}^{c h}$ decrease for $e<l$ and increases for $e>l$. At the minimum at $e=l$ the function attains the value of 0 . For all other values of $e$ it must therefore attain positive values. This proves proposition 3 .

Given the expressions for the aggregate utility for both types of consumers social surplus at symmetric solutions is therefore

$$
W(p, s)=(A+l s-p)(A+l s+p)+\beta B+\beta e s-\beta b / 4-c s^{2}
$$

which can be rewritten as

$$
W(p, s)=A^{2}+\beta B-\beta b / 4+2(A l+b w) s+\left(l^{2}-c\right) s^{2}-p^{2}
$$

As at $e=l$ prices and service levels are same under RPM and without RPM, it is obvious that the social surplus is also the same in both situations. We denote by $W_{c}$ resp. $W_{R P M}$ the value of $W$, if the arguments $\left(p_{c}, s_{c}\right)$ resp. $\left(p_{R P M}, s_{R P M}\right)$ are inserted.

We consider now an increase in $e$ which induces an increase in $w$ without changing any of the remaining parameters. As monotonocity and concavity properties are preserved whether $e$ or $w$ are taken as variables, we will use $w$ as this entails a more convenient notation.

$$
\text { (7) } \frac{\partial W}{\partial w}=2 b s+2(A l+b w) \frac{\partial s}{\partial w}+\left(l^{2}-c\right) 2 s \frac{\partial s}{\partial w}-2 p \frac{\partial p}{\partial w}
$$

Note that $\left(p_{R P M}, s_{R P M}\right)$ do not depend on $w$. Therefore

$$
\frac{\partial W_{R P M}}{\partial w}=2 b \frac{a l}{2 c-l^{2}}
$$

While this derivative is independent of the value of $w$, the derivative of $W_{c}$ will in general depend on $w$. In order to calculate the derivative of $W_{c}$ at $w=$ $d l(e=l)$ we need the derivative of $s$ with respect to $w$ at $d l$ :

$$
\frac{\partial s}{\partial w}=\frac{a}{(1+d)\left(2 c-l^{2}\right)}
$$

The derivative of $p$ with respect to $w$ at $d l$ is : 


$$
\frac{\partial p}{\partial w}=\frac{a l}{(1+d)\left(2 c-l^{2}\right)}
$$

Inserting these values in (7) yields at $w=d l$

$$
\begin{aligned}
\frac{\partial W_{c}}{\partial w}=2 b \frac{a l}{2 c-l^{2}}+2(A l+b w) \frac{a}{(1+d)\left(2 c-l^{2}\right)}+\left(l^{2}-c\right) & \frac{2 a l}{2 c-l^{2}} \frac{a}{(1+d)\left(2 c-l^{2}\right)} \\
& -\frac{2 a c}{2 c-l^{2}} \frac{a l}{(1+d)\left(2 c-l^{2}\right)} \\
= & \frac{2 b a l}{2 c-l^{2}}+\frac{2 a(A l+b d l)}{(1+d)\left(2 c-l^{2}\right)}-\frac{2 a^{2} l}{(1+d)\left(2 c-l^{2}\right)}
\end{aligned}
$$

Recalling that $b d$ equals $\beta / 2$ and $a=A+\beta / 2$ this can be simplified to

$$
\frac{\partial W_{c}}{\partial w}=\frac{2 b a l}{2 c-l^{2}}
$$

From this it follows that

$$
\left.\frac{\partial\left(W_{c}-W_{R P M}\right)}{\partial w}\right|_{w=d l}=0 .
$$

Therefore we need the second derivative of $W_{c}$ with respect to $w$. As $W_{R P M}$ is linear in $w$, its second derivative is 0 . The second derivative of $W_{c}$ has the following form:

$$
\text { (8) } \begin{aligned}
\frac{\partial^{2} W_{c}}{\partial w^{2}}=4 b \frac{\partial s_{c}}{\partial w}+(2 A l+2 b w) \frac{\partial^{2} s_{c}}{\partial w^{2}}+2\left(l^{2}-c\right)\left[\left(\frac{\partial s_{c}}{\partial w}\right)^{2}-s_{c} \frac{\partial^{2} s_{c}}{\partial w^{2}}\right] \\
-2\left[\left(\frac{\partial p_{c}}{\partial w}\right)^{2}+p_{c} \frac{\partial^{2} p_{c}}{\partial w^{2}}\right]
\end{aligned}
$$

At $w=d l$ the second derivative of $p_{c}$ and $s_{c}$ with respect to $w$ are:

$$
\frac{\partial^{2} p_{c}}{\partial w^{2}}=\frac{2 a\left(c-l^{2}\right)}{(1+d)^{2}\left(2 c-l^{2}\right)^{2}} \quad \frac{\partial^{2} s_{c}}{\partial w^{2}}=\frac{-2 a l}{(1+d)^{2}\left(2 c-l^{2}\right)^{2}}
$$


Inserting all of these expressions into (8) gives:

$$
\frac{\partial^{2} W_{c}}{\partial w^{2}}=\frac{2 a}{(1+d)^{2}\left(2 c-l^{2}\right)^{3}}\left[2 b\left(2 c-l^{2}\right)^{2}+\beta\left(2 c^{2}-3,5 c l^{2}+l^{4}\right)+A c\left(l^{2}-4 c\right)\right]
$$

The sign of this expression equals obviously the sign of the expression in brackets. As the last term is negative according to assumption A1, sufficiently large A will yield a negative sign. In this case $W_{c}$ is locally concave. And so is $W_{c}-W_{R P M}$. It has a maximum at $e=l$ where it attains the value of 0 . This proves part (a) of proposition 4.

Conversely, if $b$ is sufficiently large, then the expression in brackets becomes positive. Hence $W_{c}-W_{R P M}$. is locally convex and attains its minimum at at $e=$ $l$ where it attains the value of 0 . This proves part (b) of proposition 4 .

Norbert Schulz, Lehrstuhl VWL 3, Universität Würzburg, Sanderring 2, 97070 Würzburg

norbert.schulz@mail.uni-wuerzburg.de 